\title{
ALGUNAS REFLEXIONES SOBRE LA INFORMACIÓN CONTABLE DE LOS EMPRESARIOS EN LA LEGISLACIÓN MERCANTIL. EL DEBER DE SECRETO Y SUS EXCEPCIONES*
}

\author{
Arantza Martínez Balmaseda \\ Profesora Adjunta de Derecho Mercantil \\ Universidad del País Vasco/Euskal Herriko Unibertsitatea
}

Orcid: 0000-0002-7138-3294

Recibido el 15 de septiembre de 2016

DOI: $10.1387 /$ lan-harremanak.17492

Aceptado el 20 de octubre de 2016

\section{ABSTRACT}

Resumen: El objetivo de este trabajo es analizar el deber de llevanza de la contabilidad que pesa sobre el empresario con especial atención sobre la formulación de las cuentas anuales. Esta contabilidad presenta interés no solo desde el punto de vista interno de la empresa, como modo de organización del empresario, sino que también resulta valiosa desde el punto de vista de los terceros (socios, acreedores, trabajadores) desde el momento que ofrece una importante información para la toma de decisiones. Por ello, el principio general de secreto de contabilidad reconocido en la legislación presenta importantes excepciones en atención a la tutela de estos terceros y en el que también centraremos nuestra atención.

* Este trabajo se enmarca dentro del Proyecto de Investigación titulado «Los conflictos de intereses en las sociedades y entidades no lucrativas. Modificaciones estructurales y Derecho de grupos", DER2015-69549-P, financiado por el Ministerio de Economía y Competitividad para el periodo 2016-2019 y cuyo investigador principal es el Prof. Alberto Emparanza. 
Palabras clave: sociedades; contabilidad; cuentas anuales; secreto de la contabilidad; excepciones al secreto de la contabilidad

Abstracy: The aim of this paper is to analyze the spanish accounting system and specially the formulation of the annual accounts. This accounting is interesting not only from the internal point of view of the company, as a way of organizing the company, but presents interest from the point of view of third parties (partners, creditors or workers) because it provides valuable information to make a decision. Therefore, the general principle of confidentiality of accounting recognized in legislation presents important exceptions in attention to the protection of these third parties, and that also we will analyze in this article.

Keywords: company; accounting; annual accounts; confidentiality of accounting; exceptions of the accounting confidentiality

Laburpena: Lan honen helburua enpresari guztiak derrigorrez eman behar duten kontabilitatea aztertzea da eta batez ere urteko kontuak egiteko obligazioa. Kontabilitate honek interesa dauka ez bakarrik enpresaren barneko ikuspuntutik, empresa antolatzeko modu bat bezala, baizik eta enpresariarekin erlazionatzen diren hirugarrenek bere erabakiak hartzeko tresna baliagarria delako (bazkideak, hartzekodunak, langileak). Horregatik, nahiz eta enpresariaren kontabilitatea sekretua izan, printzipio orokor honek salbuespen garrantzitsuak dauzka eta lan honetan ere landuko ditugunak.

Hitz gakoak: sozietateak, kontabilitatea, urteko kontuak; kontabilitatearen sekretua; sekretuaren salbuespenak 


\section{SUMARIO}

Sumario: 1. Introducción. 2. El deber de llevanza de la contabilidad del empresario. 2.1. Los libros del empresario: obligatorios y potestativos. 2.1.1. Los libros obligatorios para toda clase de empresario. 2.1.2. Otros libros obligatorios según el tipo de empresario. 2.1.3. Libros potestativos. 2.2. Obligaciones formales. 3. Las cuentas anuales. 3.1. Documentos integrantes de las cuentas anuales. 3.1.1. El balance. 3.1.2. La cuenta de pérdidas y ganancias. 3.1.3. El estado que refleje los cambios en el patrimonio neto. 3.1.4. El estado de flujos de efectivo. 3.1.5. La memoria. 3.2. La información contable según el sujeto obligado. 3.2.1. Formato normal. 3.2.2. Cuentas anuales abreviadas. 3.2.3. 3 Cuentas anuales PYME-s. 3.2.4. Microempresas. 3.3. Formulación, aprobación y depósito de las cuentas anuales. 4. El secreto de la contabilidad y sus excepciones. 4.1. El principio general de secreto de la contabilidad. 4.2. Excepciones al deber de secreto de la contabilidad. 4.2.1. Publicidad de las cuentas anuales. 4.2.2. La comunicación y la exhibición de la contabilidad. 4.2.3. Publicidad de la contabilidad frente a las Administraciones Públicas 4.3. Eficacia probatoria de la contabilidad. 5. Bibliografía.

\section{Introducción}

El deber de contabilidad del empresario supone, hoy día, una pieza angular del Derecho Mercantil. Históricamente los libros de contabilidad fueron llevados de forma voluntaria por los comerciantes y en su propio interés para conocer la situación de su negocio. En este sentido, la contabilidad constituye un potente instrumento de organización para el propio empresario que le posibilita conocer día a día la marcha de las operaciones, la situación de los negocios y el rendimiento de los mismos posibilitándole adoptar decisiones teniendo en cuenta las consecuencias económicas que tendrá sobre el patrimonio.

No obstante, la contabilidad no solo ofrece interés desde el punto de vista interno de organización del empresario sino que supone también un importante instrumento para los terceros (posibles inversores, acreedores del empresario, socios, trabajadores de una empresa...) desde el momento en que constituye un instrumento importante en la toma de decisiones. Además, también el propio Estado está interesado en conocer la verdadera situación y los resultados de la empresa y de la actividad del empresario al ser éste, en definitiva, un reflejo 
de la evolución de la economía. Por ello, fruto de la evolución histórica, la contabilidad ha pasado de ser un instrumento meramente interno de organización del empresario a ser una obligación legal en aras a proteger intereses de terceros. La obligación de llevanza de la contabilidad se impone al empresario en interés del tráfico mercantil por los riesgos implicados en esta clase de actividad y por la confianza que reclama el crédito. En este sentido, hoy en día todo empresario está obligado a llevar una contabilidad ordenada y adecuada a la actividad de su empresa contabilizando diariamente las operaciones mercantiles (art. 25 CCom).

Partiendo de la anterior premisa, el objetivo de este trabajo se centra en determinar cuál es la contabilidad que los empresarios deben llevar de manera obligatoria, en función de la forma que adopte el empresario y sus dimensiones, así como determinar los supuestos en los que dicha información puede ser pública para que cualquier tercero pueda acceder a ella. En este sentido, si bien con carácter general la contabilidad del empresario es secreta y forma parte de su secreto profesional también es cierto que este principio general conoce importantes excepciones mediante las cuales se otorga publicidad a la información contable precisamente en aras a la protección de los intereses de los terceros. En este sentido, en una economía resulta necesaria que los agentes económicos posean la información relevante para la adopción de sus decisiones. Con la finalidad de intensificar la información dirigida al mercado, para que resulte más completa, veraz y accesible, se imponen deberes de transparencia a determinados sujetos con un contenido obligatorio, en el que destaca la publicidad de parte de la información contable.

\section{El deber de llevanza de la contabilidad del empresario}

Todo empresario mercantil está obligado a llevar, una contabilidad ordenada y adecuada a la actividad de su empresa, que permita el seguimiento cronológico de todas sus operaciones (art. 25 CCom) (Broseta y Martínez, 2016: 108-120; Rojo, 2015; Eizaguirre, 2005: 263-303; Vicent, 2004: 161-211) ${ }^{1}$.

1 El marco general de la actividad de la contabilidad en Espańa está contenida en los arts. 25 y ss. del Código de Comercio, arts. 253 y ss. de la Ley de Sociedades de Capital, el Reglamento de Registro Mercantil, el RD 1514/2007, de 16 de noviembre, por el que se aprueba el Plan General de Contabilidad., las normas internacionales de información financiera y las normas para la formulación de las cuentas consolidadas. Además de ello y en cuanto a la auditoría de cuentas es aplicable Ley 22/2015, de 20 de julio, de Auditoría de Cuentas, el Reglamento de Auditoría de Cuentas, aprobada mediante Real Decreto 1517/2011 y las nuevas normas técnicas de auditoría se aprobaron por la Resolución de 15 de octubre de 2013, del Instituto de Contabilidad y Auditoría de Cuentas. 
El deber recae sobre el propio empresario, si es persona natural y en el caso de las sociedades mercantiles esta llevanza corresponde a los administradores (Broseta y Martínez, 2016: 108; Eizaguirre, 2005: 263). Este deber puede ser cumplido bien directamente por los sujetos obligados bien por medio de personas autorizadas. Tales personas pueden ser dependientes del empresario, vinculados a éste por medio de un contrato de trabajo o, por el contrario, ser profesionales independientes o sociedades profesionales con los que se ha concluido un contrato de arrendamiento de servicios. Salvo prueba en contra se presumirá que quien ha confeccionado la contabilidad se encontraba autorizado para ello por el empresario. La llevanza de la contabilidad por persona autorizada no exime de responsabilidad al empresario ni a los administradores (art. 25.2 CCom).

Como hemos adelantado, es una obligación que se impone a todo empresario, sea persona natural o jurídica, pero no obstante, esta obligación se ve modulada en función de las dimensiones de la empresa y el sector económico en el que se desarrolle la actividad empresarial. De esta manera, no es la misma contabilidad la que tiene que llevar un pequeño empresario que la que le corresponde a una gran sociedad mercantil teniendo en cuenta también que en función del sector económico existen determinadas entidades mercantiles sometidas a regímenes especiales de supervisión administrativa (entidades de crédito, entidades de seguros...) (Rojo, 2015: 117).

\subsection{Los libros de los empresarios: obligatorios y potestativos}

\subsubsection{Libros obligatorios para toda clase de empresarios}

El Código de Comercio impone a todo empresario la obligación de llevar un libro de Inventarios y Cuentas Anuales y otro Diario, sin perjuicio de lo establecido en las leyes o disposiciones especiales (art. 26 C.Com) (Eizaguirre, 2005: 277; Broseta y Martínez, 2016: 109; Rojo, 2015: 122).

El inventario comprende el balance inicial detallado de la empresa y han de transcribirse al menos trimestralmente los balances de comprobación (balance de sumas y saldos), y se cierra al terminar el ejercicio anual transcribiendo también el inventario final y las cuentas anuales (Eizaguirre, 2005: 281; Broseta y Martínez, 2016: 109-110). Estas últimas, se componen del balance, la cuenta de pérdidas y ganancias, el estado que refleje los cambios en el patrimonio neto, el estado de flujos de efectivo y la memoria.

El libro Diario recoge todas las operaciones relativas a la actividad de la empresa (art. 28.2 CCom). Aunque se afirma inicialmente que las operaciones deben de ser registradas día a día, será válida, sin embargo, la anotación conjunta de los totales de las operaciones por períodos no superiores al trimestre, a condición de que su detalle aparezca en otros libros o registros concordantes, de acuerdo con la naturaleza de la actividad de que trate. 


\subsubsection{Otros libros obligatorios según el tipo de empresario}

No obstante, el libro Inventarios y Cuentas Anuales y el Libro Diario no son los únicos libros obligatorios a que se refiere el Código de Comercio sino que en función del tipo de empresario existen también otros libros obligatorios (Eizaguirre, 2005: 277; Broseta y Martínez, 2016: 110):

— Libro de actas: las sociedades mercantiles, cualquiera que sea la forma social, deben de llevar un libro de actas en el que transcribirán, al menos, los acuerdos adoptados por las juntas o asambleas generales o especiales de socios y por los demás órganos colegiados que pudiera tener la sociedad (Consejo de Administración, Comisión Delegada o Ejecutiva). La Ley exige que toda sociedad lleve, cuando menos, un libro de actas pero permite que, en lugar de uno, lleve dos o más (uno para acuerdos adoptados por las Juntas o asambleas de socios y otro para los acuerdos del Consejo de Administración) (art. 26 CCom).

- Libro registro de acciones nominativas: de llevanza obligatoria únicamente para las sociedades anónimas y en comandita por acciones. En ella se debe hacer mención expresa de a quién pertenece cada acción de la sociedad, ya sea persona física o jurídica (art. 116 LSC).

— Libro registro de socios: de llevanza obligatoria únicamente para sociedades limitadas. En ella se debe hacer mención expresa de a quién pertenece cada participación social de la sociedad. (art. 104 LSC).

- Libro registro donde se transcriben los contratos celebrados entre el socio único y la sociedad y de llevanza obligatoria para sociedades unipersonales SA y SL (art. 16 LSC)

\subsubsection{Libros potestativos}

Además de los libros obligatorios de contabilidad los empresarios podrán llevar los demás libros o registros que estimen convenientes según el sistema de contabilidad que adopten o la naturaleza de la actividad que desarrollen (Eizaguirre, 2005: 277; Rojo, 2015: 122-123). Destaca por su difusión práctica el Libro Mayor que facilita el seguimiento personalizado de las operaciones económicas a través de un sistema de cuenta corriente con proveedores y clientes. En cambio para las aseguradoras la llevanza del Libro Mayor es obligatoria y recogerá para una de las cuentas, los cargos y abonos que en ellas se realicen, debiendo concordar en todo momento con las anotaciones realizadas en el Libro Diario ( art. 96.1 LOSS.EAR).

\subsection{Obligaciones formales}

El Código de Comercio exige además que se cumplan unos requisitos de forma en la llevanza de esta contabilidad. 
De esta manera, desde el punto de vista formal se exige, en primer lugar, que la contabilidad sea llevada en libros, que han de recoger de manera sistemática, en un cuerpo continuo de páginas, las operaciones de la empresa. El soporte material de la contabilidad son, por lo tanto, los libros que pueden ser libros encuadernados y foliados, en los que se manuscriben los asientos y estados contables, o bien, listados de ordenador u hojas sueltas que anualmente se encuadernan tras el cierre del ejercicio. No es contabilidad, por tanto, aquella que consiste en la mera acumulación de legajos y hojas en los que consten cifras relativas a las operaciones (Rojo, 2015: 123).

En segundo lugar, es necesario también que estos libros sean llevados con claridad, por orden de fechas, sin espacios en blanco, interpolaciones, tachaduras ni raspaduras (art. 29 CCom). Por tanto, cuando se detecte un error o una omisión en los mismos, las modificaciones para su corrección deberán efectuarse en el momento de su detección, a continuación de la última anotación realizada, y no modificando el error, ni incluyendo la omisión en la fecha en que se debió anotar.

En tercer lugar, estos libros ${ }^{2}$ deben ser presentados para su legalización en el Registro Mercantil del lugar donde el empresario tenga su domicilio (art. 27 CCom) cuatro meses después del cierre del ejercicio. Mediante la legalización el Registro sella los libros con la finalidad de que su información no se pueda manipular con posterioridad. De esta manera, la legalización de los libros otorga a éstos una presunción de legitimidad en la medida que impide que se reconstruya por el empresario en función de la conveniencia de una situación determinada. La Ley 14/2013, de 28 de septiembre, de apoyo a los emprendedores y su internacionalización ha modificado el procedimiento de legalización y establece que la legalización de los libros de llevanza obligatoria por parte de los empresarios se llevará a cabo telemáticamente ante el Registro Mercantil. Dicho sistema de legalización telemática de los libros no es obligatorio para los libros de llevanza voluntaria ni conlleva alteración alguna en los sujetos obligados a la legalización ni al objeto de la misma ${ }^{3}$.

Y finalmente, pesa una obligación de conservación de todos los libros, correspondencia, documentación y justificantes concernientes a su actividad empresarial de los últimos seis años, independientemente de que se continúe o no

2 No solo deben ser objeto de legalización los libros obligatorios de contabilidad también tienen que ser legalizados los demás libros de llevanza obligatoria para el empresario (art. 27. 3 CCom).

3 Con el objetivo de cumplir con el nuevo sistema obligatorio de presentación telemática y al mismo tiempo cumplir con la confidencialidad y protección de la información remitida por los empresarios, la Instrucción de 1 de julio de 2015 de la DGRN delimita ciertos mecanismos técnicos precisos para mantener dicha confidencialidad y establece la posibilidad de que sean los propios interesados los que decidan el grado de seguridad y confidencialidad en la remisión de la información y clarifica determinados aspectos prácticos para la aplicación del nuevo sistema de legalización telemática todo ello mediante la emisión de siete instrucciones. 
en el ejercicio de la actividad. Si el cese de la actividad viene motivado por causa de defunción tal responsabilidad recaerá sobre sus herederos. Si viene motivado por disolución los responsables de la conservación serán sus liquidadores.

\section{Las cuentas anuales}

Como hemos adelantado todo empresario, persona natural o jurídica, tiene el deber de formular cuentas anuales al cierre del ejercicio. Este deber pesa sobre los empresarios en general (art. 34.1 CCom) aunque en el ámbito de las sociedades de capital este deber no recae sobre el empresario, que sería la persona jurídica, sino sobre los administradores sociales (art. 253.1 LSC) siendo además una de las competencias que los administradores no pueden delegar ni siquiera en comisiones ejecutivas designadas en el seno del consejo de administración (art. 249 bis LSC). En consecuencia todos los administradores deben asumir la autoría jurídica de los documentos integrantes de las cuentas anuales así como del informe de gestión, que por regla general, junto con la propuesta sobre la aplicación del resultado, también habrán de redactar, con independencia de cuál haya sido la autoría material, en la que puede que no hayan participado todos — comisiones ejecutivas o reparto de funciones entre administradores solidarios - o hayan recurrido a terceros especialistas. De ahí que todos los administradores deban firmar las cuentas y el informe de gestión (arts. 252.2 TRLSC y art. 37 CCOm) (López, 2013: 582; Broseta y Martínez, 2016: 117; Rojo, 2013: 132).

Las cuentas anuales están integradas por el balance, la cuenta de pérdidas y ganancias, el estado que refleje los cambios en el patrimonio neto, el estado de flujos de efectivo y la memoria y tienen por finalidad mostrar la evolución del patrimonio empresarial y su rentabilidad. Estos documentos forman una unidad y para que cumplan su función deben redactarse conforme a los principios de la contabilidad material establecidos en el CCom (arts. 34 y 38) y a unos modelos establecidos en el RD 1514/2007, de 16 de noviembre, por el que se aprueba el Plan General de Contabilidad entre los que el TRLSC destaca el de unidad, el de claridad y el de fidelidad ( 254. 2 LSC) (Eizaguirre, 2005: 263; Broseta y Martínez, 2016: 115; López, 2013: 577; Girón, 1993: 9 y ss.; Arana, 2000: 20 y ss.).

No obstante, en función del tamaño que presente el empresario la obligación de presentar cuentas anuales se ve modulada. En este sentido, en el caso de las sociedades mercantiles estas podrán optar por un formato normal, abreviado o de PYMES en función de unos criterios previamente establecidos.

\subsection{Documentos integrantes de las cuentas anuales}

Las cuentas anuales comprenden el balance, cuenta de pérdidas y ganancias, memoria, estado de cambios de patrimonio neto y estado de flujos de efectivo y 
la memoria ${ }^{4}$. Estos documentos forman una unidad, y deberán reflejar la imagen fiel del patrimonio, de la situación financiera y de los resultados de la empresa (art. 34.2 CCom y 254.2 LSC) (Alcover, 2011: 171 y ss.; López, 2013: 577-632).

\subsubsection{El balance}

El balance es el documento contable que refleja el patrimonio de una empresa, esto es, los bienes, derechos y obligaciones que tiene en un momento dado. Para ello en el balance figurarán de forma separada el activo, el pasivo y el patrimonio neto (Eizaguirre, 2005: 290; López, 2013: 582; Broseta y Martínez, 2016: 113).

El activo comprenderá con la debida separación el activo fijo o no corriente y el activo circulante o corriente. Para determinar la adscripción de los elementos patrimoniales del activo a una u otra categoría se tendrá en cuenta su afectación; es el empresario, quien, en función de las características de la actividad empresarial, determina qué elementos se integran en el activo fijo y cuáles en el circulante. El activo circulante o corriente comprenderá los elementos del patrimonio que se espera vender, consumir o realizar en el transcurso del ciclo normal de la explotación, así como, con carácter general, aquellas partidas cuyo vencimiento, enajenación o realización, se espera que se produzca en un plazo máximo de un año contado a partir de la fecha de cierre del ejercicio. Los demás elementos del activo deben clasificarse como fijos o no corrientes (art. 35.1 CCom).

En el pasivo se diferenciarán el pasivo no corriente y el pasivo circulante o corriente. El pasivo circulante o corriente comprenderá, con carácter general, las obligaciones cuyo vencimiento o extinción se espera que se produzca durante el ciclo normal de explotación, o no exceda el plazo máximo de un año contado a partir de la fecha de cierre del ejercicio. Los demás elementos del pasivo deben clasificarse como no corrientes. Las provisiones u obligaciones en las que exista incertidumbre acerca de su cuantía o vencimiento figurarán de forma separada.

En el patrimonio neto se diferenciarán, al menos, los fondos propios de las restantes partidas que lo integran.

En consecuencia, la información suministrada por el balance es importante desde el momento en que el análisis de un balance permite conocer la situación patrimonial de una empresa (conocer si tiene bienes suficientes para atender sus

\footnotetext{
${ }^{4}$ El estado de cambios de patrimonio neto y estado de flujos de efectivo no resultarán obligatorios para empresas que puedan (aunque no necesariamente elaboren) el balance en formato abreviado (art. 34.1 CCom y arts. 254.1 y 257.3 LSC).
} 
obligaciones), así como, en cierta medida, su situación financiera (conocer si sus activos líquidos son suficientes para atender sus deudas a corto plazo).

\subsubsection{La cuenta de pérdidas y ganancias:}

Está íntimamente unida al balance siendo un complemento de ésta. La cuenta de pérdidas y ganancias es el documento contable que recoge el resultado del ejercicio y, tal vez con mayor importancia, el modo en que se ha generado este resultado (esto es, los ingresos y gastos concretos que lo han generado este resultado) (Eizaguirre, 2005: 290; López, 2013: 583; Broseta y Martínez, 2016: 113: Rojo, 2015: 134; Alcover, 2011: 171 y ss.).

Mientras que el balance muestra la situación patrimonial y financiera de la empresa en un momento dado, la cuenta de pérdidas y ganancias ofrece una visión dinámica del ejercicio indicando el empleo de los recursos empresariales y cuáles han sido las causas de la existencia de beneficio o pérdidas (Rojo, 2015: 134), separando los ingresos y los gastos del mismo y diferenciando entre los resultados ordinarios de explotación y los extraordinarios. Para ello agrupará las diferentes partidas según su naturaleza, figurando de forma separada al menos: la cifra de negocios, el consumo de existencia, las dotaciones a la amortización, las correcciones valorativas, las variaciones de valor derivadas de la aplicación del criterio del valor razonable, los ingresos y gastos financieros, las pérdidas y ganancias originadas por la enajenación de activos y el gasto por impuestos sobre beneficios.

Por tanto, desde una perspectiva jurídica (sobre todo, cuando se analice la solvencia y viabilidad de una compañía en sede concursal, o cuando se produzca una fusión o compraventa de empresas), resultará relevante conocer no solo los resultados del ejercicio de una empresa, sino la forma en que se generan estos resultados (Gurrea, 2016).

\subsubsection{El estado que refleje los cambios en el patrimonio neto}

El estado de cambios en el patrimonio neto (ECPN) es un documento contable introducido en Espańa a través de la Ley 16/2007 de Reforma Contable que solo resulta obligatorio (aunque desde una reciente reforma de la legislación mercantil con motivo de la promulgación de la nueva Ley de Auditoría) para las sociedades obligadas a la formulación de balance normal. Este documento contable se divide en dos partes (López, 2013: 584; Broseta y Martínez, 2016: 114; Rojo, 2015: 134):

(i) un estado de ingresos y gastos reconocidos (que, recordemos, no es obligatorio para las empresas que se acojan al PGC de pymes). Se trata de los ingresos y gastos generados por la actividad durante el ejercicio, diferenciados los que figuran en la cuenta de pérdidas y ganancias y los registrados directamente en el patrimonio neto. 
(ii) un estado total de cambios en el patrimonio neto. Se trata de todos los movimientos del patrimonio neto, incluidas las transacciones con los socios o propietarios, así como la información relativa a los ajustes en el patrimonio neto realizados como consecuencia de cambios de criterios contables y corrección de errores (Gurrea, 2016).

\subsubsection{El estado de flujos de efectivo}

Se trata de un estado contable en el que se muestran agrupados y ordenados los cobros y pagos informando así de los movimientos de efectivo producidos en el ejercicio (aunque solo para las empresas que tuvieran el deber de elaborar balance normal).

\subsubsection{La memoria}

La memoria es el documento contable que completa, amplía y comenta la información contenida en el balance, la cuenta de pérdidas y ganancias, el estado de cambios en el patrimonio y el estado de flujos de efectivo para suministrar toda la información necesaria para obtener la imagen fiel de la empresa, cuando de los demás estados no se deduzca con claridad. Con tal objetivo se pueden incluso incluir datos cualitativos relativos a la situación del ejercicio anterior (Eizaguirre, 2005: 291; Broseta y Martínez, 2016: 115; Rojo, 2015: 135).

Por tanto, su lectura resulta esencial para evitar una lectura incorrecta o insuficiente del patrimonio y la situación financiera de la compañía que podría tener repercusiones jurídicas.

Además, en los supuestos de inaplicación de disposiciones legales por contravenir el objetivo de obtención de la imagen fiel se anotará en la memoria la falta de aplicación de la normativa, la motivación que ha conllevado a tal decisión, explicando su influencia sobre el patrimonio, la situación financiera y los resultados de la empresa.

Las sociedades que formulen balance abreviado pueden formular también memoria abreviada (art. 261 LSC).

\subsection{La información contable según el sujeto obligado}

Si bien todo empresario se encuentra en la obligación de formular cuentas anuales, en función de la dimensión que presente el empresario esta obligación se ve modulada 5 . En este sentido, a excepción de aquellas entidades españolas

\footnotetext{
5 En el caso del empresario individual se pueden observar que la legislación mercantil establece unos libros obligatorios mientras que la legislación fiscal establece otros. De esta manera, el art. 25 CCom establece que todo empresario deberá llevar necesariamente, sin perjuicio de lo establecido
} 
que, de conformidad con lo previsto en el Reglamento 1606/2002, tengan que elaborar sus estados financieros de conformidad con las normas internacionales de contabilidad, existen tres formatos distintos de cuentas anuales para las empresas españolas que se diferencian en el detalle de la información que contienen (López, 2013: 587-592; Rojo, 2015: 121):

- Cuentas anuales ordinarias.

- Cuentas anuales abreviadas.

- Cuentas anuales PYMES. El caso de las microempresas.

Debemos tener en cuenta que el incumplimiento del formato adecuado puede acarrear un incumplimiento del deber de llevanza de la contabilidad. En este sentido, la formulación de un balance abreviado teniendo la obligación de formular un balance normal sería un incumplimiento del deber de llevanza de la contabilidad en el sentido que no se han elaborado del estado de flujos de efectivo y del informe de gestión o se ha elaborado la memoria y estado de cambios en el patrimonio neto en formato abreviado y no en el ordinario como debería serlo. Ello puede derivar en una sanción concursal concursalmente (art. 164.2$1 .^{\circ}$ in fine) $\mathrm{y}$, en su caso, incluso penalmente (art. 259.1-6. ${ }^{\circ} \mathrm{CP}$ ) (Gurrea, 2016).

\subsubsection{Formato normal}

Las cuentas anuales normales están recogidas en el RD 1514/2007, de 16 de noviembre, por el que se aprueba el Plan General de Contabilidad. En principio, todas las sociedades están obligadas a su presentación, a excepción de aquellas que pueden presentar las cuentas anuales abreviadas o de aquellas que pueden acogerse al Plan General de Contabilidad de PYME-s (López, 2013: 587).

Asimismo, conviene tener en cuenta que, aquellas entidades obligadas a la formulación del balance normal, junto al depósito de las cuentas anuales (que, en estos casos, integrarán el balance, cuenta de pérdida y ganancias, estado de cambios de patrimonio neto, estado de flujos de efectivo y memoria), también deberá procederse al depósito del informe de gestión (López, 2013: 592; Gurrea, 2016) (y, en todo caso, del informe de auditoría de cuentas anuales ( López, 2013: 603 y ss.; Rojo, 2015: 139 y ss.) (tras la Ley de Emprendedores, los límites cuantitati-

en las leyes o disposiciones especiales, Cuentas Anuales. Sin embargo, el Real Decreto 439/2007, de 30 de marzo, por el que se aprueba el Reglamento del Impuesto sobre la Renta de las Personas Físicas (legislación fiscal) ya empieza a distinguir entre empresarios de distintos tipos y así en su art. 68 establece que «4. Los contribuyentes que desarrollen actividades empresariales cuyo rendimiento se determine en la modalidad simplificada del régimen de estimación directa estarán obligados a la llevanza de los Libros seńalados en el apartado anterior.» Y en el párrafo anterior se especifican los siguientes libros: Libro registro de venta e ingresos/Libro registro de compras y gastos/Libro registro de bienes de inversión. 
vos para la obligación de auditar resultan inferiores a los del balance normal y, por tanto, toda entidad que, obligatoriamente, tenga que formular informe de gestión, necesariamente, tendrá la obligación de auditar) (Gurrea, 2016).

\subsubsection{Cuentas anuales abreviadas}

La principal diferencia entre las cuentas anuales normales y las abreviadas radica en su simplicidad. Las cuentas anuales abreviadas tienen un formato más simple, donde hay una menor desagregación de la información; no hay normas especiales definidas para este tipo de documentos.

Podrán formular el balance, la memoria y el estado de cambios en el patrimonio neto abreviados las sociedades que durante dos ejercicios consecutivos reúnan, a la fecha de cierre de cada uno de ellos, al menos dos de las siguientes circunstancias (López, 2013: 587; Rojo, 2015: 133):

- Que el total de las partidas del activo no supere los cuatro millones de euros.

- Que el importe neto de su cifra anual de negocios no supere los ocho millones de euros.

- Que el número medio de trabajadores empleados durante el ejercicio no sea superior a cincuenta.

La cuenta de pérdidas y ganancias tiene límites cuantitativos propios. En cuanto a la cuenta de pérdidas y ganancias, las sociedades podrán presentarla en su formato abreviado cuando, durante dos ejercicios consecutivos, reúnan a la fecha de cierre de cada uno de ellos, al menos dos de las siguientes circunstancias:

- Que el total de las partidas de activo no supere los once millones cuatrocientos mil euros.

- Que el importe neto de su cifra anual de negocios no supere los veintidós millones ochocientos mil euros.

- Que el número medio de trabajadores empleados durante el ejercicio no sea superior a doscientos cincuenta.

No existe un estado de flujos de efectivo en modelo abreviado y las empresas que puedan presentar el balance, la memoria y el estado de cambios en el patrimonio neto abreviados, están eximidos de presentar este documento.

\subsubsection{Cuentas anuales PYME-s}

El RD 1515/2007 formula un Plan General Contable para PYMES, con ciertas diferencias en criterios de valoración y en la formulación de las cuentas anuales. 
Podrán optar por utilizar el modelo PYME de cuentas anuales, tanto para el balance como para la cuenta de pérdidas y ganancias las sociedades que cumplan los siguientes requisitos (López, 2013: 589; Rojo, 2015: 133):

- Que el total de las partidas del activo no supere los 2.800.000 euros.

- Que el importe neto de su cifra anual de negocios no supere los 5.700.000 euros.

- Que el número medio de trabajadores empleados durante el ejercicio no sea superior a 50 .

El modelo PYME es el que utilizan la mayor parte de las microempresas de nuestro país. La opción elegida por la empresa para formular las cuentas deberá mantenerse tres ejercicios consecutivos.

Las PYME-s pueden decidir entre aplicar el PGC en su versión íntegra o en la versión específica para PYME-s. Además, las sociedades que apliquen la versión íntegra del PGC, pueden elaborar modelos abreviados de las cuentas anuales si cumplen los requisitos necesarios para su aplicación.

\subsubsection{Microempresas}

Las microempresas se acogen al PGC para PYME-s pero pueden aplicar unos criterios específicos de registro y valoración. Se consideran microempresas todas las empresas que, habiendo optado por aplicar el PGC de PYME-s, durante dos ejercicios consecutivos reúnan, a la fecha de cierre de cada uno de ellos, al menos dos de las siguientes circunstancias (López, 2013: 590):

- Que el total de las partidas del activo no supere el millón de euros.

- Que el importe neto de su cifra anual de negocios no supere los dos millones de euros.

- Que el número medio de trabajadores empleados durante el ejercicio no sea superior a diez.

\subsection{Formulación, aprobación y depósito de las cuentas anuales}

Las cuentas anuales deben ser formuladas en el plazo máximo de tres meses desde la fecha de cierre del ejercicio. Una vez formuladas las cuentas anuales deben aprobarse en el plazo máximo de seis meses desde la fecha de cierre del ejercicio social (art. 164.1 LSC). Y durante el mes siguiente a la aprobación, los administradores tendrán el deber de depositar las cuentas anuales en el Registro Mercantil del domicilio social (Díaz, 2002: 2095 y ss.; Del Puerto, 2011: Alcover, 2011: 171 y ss.; Boquera, 2002: 2069 y ss.; Campins, 2012: 423 y 
ss.), junto con el informe de gestión ${ }^{6}$ (si la entidad se encontrara obligada), las cuentas anuales consolidadas (si la compañía fuera la sociedad dominante de un grupo de sociedades obligado a la formulación de cuentas consolidadas) ${ }^{7}$ y el informe que, en su caso, hubieran emitido los auditores de cuentas de la sociedad (art. 279 LSC) $^{8}$ (Sánchez, 2014: 361-364; Gallego, 2014: 10-17).

${ }^{6}$ Es un documento contable que no forma parte de las cuentas anuales y solo resulta obligatorio para las empresas que deban formular el balance normal. Debe ser elaborado por los administradores de la sociedad, y contener una exposición fiel sobre la evolución de los negocios y la situación de la sociedad, así como los principales riesgos e incertidumbres a los que se enfrenta la empresa. Junto con las cuentas anuales y, en su caso, el informe de auditoría, deberá ser objeto de depósito en el Registro Mercantil.

7 Toda sociedad dominante de un grupo de sociedades está obligada, en principio, a formular cuentas anuales consolidadas, que comprenderán un balance consolidado, una cuenta de pérdidas y ganancias consolidada, un estado de cambios en el patrimonio neto consolidado, un estado de flujos de efectivo consolidado y una memoria consolidada (art. 44.1 CCom). La ley exige que las cuentas anuales consolidadas vayan acompañados, en todo caso, del informe de gestión consolidado y del informe de auditoría de cuentas anuales consolidadas (art. 42.4 y 42.6 CCom). En consecuencia, junto a la formulación de sus propias cuentas anuales individuales, toda sociedad dominante de un grupo de sociedades tienen el deber de elaborar unos estados contables que reflejen la situación económico-financiera y patrimonial del grupo. Existen varias excepciones a la obligación de consolidar: (i) en función del escaso tamaño del grupo; (ii) por la existencia de subgrupo; y (ii) por la escasa importancia relativa de las sociedades dependientes. Las cuentas anuales consolidadas deben formularse de conformidad con dos posibles marcos normativos de información financiera. Por un lado, deberán elaborarse de conformidad con lo previsto en las normas internacionales de información financiera aprobadas por la Unión Europea (NIIF-UE) si, a la fecha de cierre del ejercicio, alguna de las sociedades del grupo ha emitido valores admitidos a cotización en un mercado regulado de cualquier Estado miembro de la Unión Europea. No obstante, si ninguna de las sociedades del grupo tuviera valores admitidos a cotización las cuentas anuales podrán elaborarse conforme a las normas contables españolas. Estas normas contables nacionales comprenderán, principalmente, el Código de Comercio (arts. 42 a 49), las normas para la formulación de las cuentas anuales consolidadas (NFCAC) y el Plan General de Contabilidad (PGC).

${ }^{8}$ En algunos supuestos en función de parámetros cuantitativos se impone a las sociedades anónimas o limitadas el deber de auditar cuentas anuales. La auditoría de cuentas es «la actividad consiste en la revisión y verificación de las cuentas anuales, asi como de otros estados financieros o documentos contables, elaborados con arreglo al marco normativo de información financiera que resulte de aplicación, siempre que dicha actividad tenga por objeto la emisión de un informe sobre la fiabilidad de dichos documentos que pueda tener efectos frente a terceros" (art. 1.2 LAC). La finalidad de la auditoría no es otra que incrementar la fiabilidad de la información financiera de las empresas.

La auditoría es obligatoria en los siguientes supuestos: 1.Cuando la compañía supere determinados cifras de activo, volumen de negocio y número medio de empleados (DA 1.a, $1 \mathrm{f}$ ) LAC). En el caso de las sociedades de capital, la auditoría es obligatoria para aquellas entidades que, durante, al menos, dos años consecutivos, superen dos de los tres siguientes parámetros (i) $2.850 .000 €$ de activos; (ii) $5.700 .000 €$ de importe neto de la cifra de negocios; y (iii) 50 trabajadores (art. 263.2 LSC). 2. Para las sociedades dominantes de un grupo de sociedades que formulen y publiquen, de manera voluntaria u obligatoria, cuentas consolidadas. 3. Aquellas entidades que, aunque no estén obligadas a auditar en función de su tamaño, un socio minoritario (5\%) hubiera solicitado, en tiempo y forma, el nombramiento de auditor (art. 265.2 LSC). 4. Cuando así lo acuerde el juez competente (art. 40 CCom). 5. Todas las sociedades cuyos títulos coticen en cualquiera de las Bolsas Oficiales de Comercio; 6 . Todas las sociedades que emitan obligaciones en oferta pública; 7 . Todas las entidades que se dediquen a la inter- 
El depósito de las cuentas anuales fuera de plazo supondrá una sanción administrativa para la sociedad (art. 283 LSC). Asimismo, cuando el depósito se demore más de un ańo desde la fecha de cierre del ejercicio correspondiente, la falta de depósito de cuentas también supondrá el cierre registral de la sociedad. Ello implica que, en la medida en que la sociedad tenga cerrado el registro, no podrá inscribir en el Registro Mercantil ningún documento, a excepción de los títulos relativos al cese o dimisión de administradores, gerentes, directores generales o liquidadores, a la revocación o renuncia de poderes, a la disolución de la sociedad y nombramiento de liquidadores, y a los asientos ordenados por la autoridad judicial o administrativa (art. 282 LSC y art. 378 RRM) (León, 1998: 282-290; Cábanas, 2001: 361-388).

En estos casos de falta de depósito de cuentas, junto a las sanciones administrativas y el posible cierre registral, los administradores de una sociedad que resulte insolvente quedarán expuestos a las sanciones previstas en la Ley Concursal (Muñoz y Muñoz, 2005: 2173-2204; García-Cruces, 2013: 179-204; Yzquierdo, 2013: 179-204; Martín, 2012: 177-204; Arribas, 2011: 97-105; Miquel, 2011: 557-573; Rodríguez, 2013: 130-178) que, en este sentido, establece una presunción iuris tantum de concurso culpable (art. 165.1-3. ${ }^{\circ}$ LC).

\section{El secreto de la contabilidad y sus excepciones}

\subsection{El principio general de secreto de la contabilidad}

Como hemos venido afirmando, la contabilidad ofrece una importante información sobre la situación patrimonial y financiera del empresario y, por ello, el propio empresario tiene interés en que los libros y los documentos contables no sean accesibles para los terceros competidores. Por ello, el ordenamiento jurídico establece como norma general el principio de que la contabilidad del empresario es secreta (art. 32.1 CCom) (Eizaguirre, 2005: 287; Rojo, 2015: 127; López, 2013: 587; Blanco, 1980: 71 y ss.).

Desde este punto de vista, la violación del secreto contable, en cuanto supone una violación de un secreto empresarial, puede ser reprimida en ciertos casos con las normas sobre competencia desleal (art. 13 LCD). Si la violación del

mediación financiera; 8 . Todas las entidades que tengan por objeto social cualquier actividad sujeta a la Ley de Ordenación del Seguro Privado, dentro de los límites que reglamentariamente se establezcan; 9. Todas las entidades que reciban subvenciones, ayudas o realicen obras, prestaciones, servicios o suministren bienes al Estado y demás Organismos Públicos dentro de los límites que reglamentariamente fije el Gobierno por Real Decreto (DA $1 .^{a}$ LAC). Viene regulado por la vigente Ley 22/2015, de 20 de julio, de Auditoría de Cuentas, el Reglamento de Auditoría de Cuentas, aprobada mediante Real Decreto 1517/2011 y las nuevas normas técnicas de auditoría del Instituto de Contabilidad y Auditoría de Cuentas se aprobadas por Resolución de 15 de octubre de 2013. 
secreto se realiza por un trabajador, el empresario podrá proceder a la extinción del contrato de trabajo por transgresión de la buena fe contractual y abuso de confianza (art. $54.2 \mathrm{~d}$ ET). Además, en el plano penal, la tutela del secreto de la contabilidad se garantiza a través del tipo general de revelación de secretos (art. 197 a 201 CP) (Rojo, 2015: 127).

\subsection{Excepciones al deber de secreto de la contabilidad}

No obstante lo anterior, en la medida en que la contabilidad cumple también una función externa de protección de los terceros el principio general de secreto de la contabilidad no es absoluto y presenta excepciones. Así, el propio Código de Comercio, después de reconocer el secreto de la contabilidad deja a salvo "lo que se derive de lo dispuesto en Leyes» (art. 32.1 CCom).

\subsubsection{Publicidad de las cuentas anuales}

Como hemos analizado, las cuentas anuales de las sociedades mercantiles $^{9}$, una vez aprobadas por la Junta General deben ser depositadas en el Registro Mercantil del domicilio social del empresario (Gómez, 2007: Selva, 1993; Cano, 2010: 50-59; Rocafort, 2010: 233-254) lo que implica que pasan a ser públicas y cualquier tercero puede acceder a la información contable allí depositada ${ }^{10}$ (León, 1997; Eizaguirre, 2005: 268). Supone una excepción al principio del secreto de la contabilidad del empresario desde el momento en que cualquier persona puede pedir una copia de las cuentas anuales y do-

9 Están obligados a depositar cuentas anuales a) Las sociedades anónimas, de responsabilidad limitada, comanditarias por acciones y de garantía recíproca, fondos de pensiones y, en general, cualesquiera otros empresarios que en virtud de disposiciones vigentes vengan obligados a dar publicidad a sus cuentas anuales b) La sociedad dominante, en los casos de grupos de sociedades que presentan cuentas consolidadas c) Las sociedades extranjeras que tengan abiertas sucursales en España. d) Las sociedades colectivas y comanditarias simples, cuando a la fecha de cierre del ejercicio todos los socios colectivos sean sociedades espańolas o extranjeras e) Las fundaciones depositarán las cuentas anuales en el Registro de Fundaciones, debiendo formular cuentas anuales consolidadas cuando la fundación se encuentre en cualquiera de los supuestos previstos para la sociedad dominante. f) El depósito de cuentas en el Registro Mercantil será potestativa para los empresarios individuales, con excepción del naviero. (arts. 365, 372 y 375 RRM, art. 41.2 CCom y Disposición Adicional Sexta de la Ley 50/2002, de Fundaciones).

${ }^{10}$ El origen de la obligación de publicar las cuentas anuales se encuentra en el Derecho anglosajón. En concreto, aparece en la legislación inglesa sobre sociedades anónimas de mediados del siglo xIx y posteriormente en la legislación americana. Este deber de publicar las cuentas anuales de las sociedades anónimas se extendió rápidamente a las legislaciones europeas si bien con peculiaridades. En España, aunque la obligación de publicar las cuentas anuales de las sociedades anónima se introduce por el Código de Comercio de 1885 la norma fue reiteradamente incumplida y se puede mantener que hasta la introducción del Derecho comunitario en el Derecho de sociedades español no existía con carácter general la obligación de publicar las cuentas anuales de las sociedades de capital. Si se dejan al lado otros aspectos más particulares, este deber se había previsto fundamentalmente en conexión con las exigencias de ordenación suscitadas en el mercado de valores y en determinados sectores económicos, la actividad de crédito y la de seguros, de particular relevancia para la economía general. 
cumentos complementarios depositados en el Registro Mercantil que se hará efectiva por medio de certificación expedida por el Registrador o por medio de copia de los documentos depositados. La solicitud podrá hacerse a través de Internet y expedirse en soporte informático. (art. 369 RRM). Los Registradores Mercantiles tienen la obligación de conservar las cuentas anuales y documentos complementarios depositados en el Registro Mercantil durante seis años a contar desde la publicación del anuncio del depósito en el BORME ( art. 377 RRM).

La finalidad de esta publicidad es que los terceros que vayan a contratar con el empresario o hayan contratado con él tengan un instrumento útil en la toma de decisiones (Eizaguirre, 2005: 289-299; Rojo, 2015: 127) intensificando la información dirigida al mercado, y procurando atender, a los intereses de distintos destinatarios-socios, acreedores, trabajadores, etc (Girón: 1993). Y es que, en este sentido, la información que proporcionan las cuentas anuales resulta relevante. La capacidad de las cuentas anuales para ser un instrumento de utilidad en la toma de decisiones se basa, en buena medida, en su capacidad para mostrar de manera fiable la imagen fiel del patrimonio, de la situación financiera y de los resultados de la empresa. Como hemos analizado, las cuentas anuales comprenden el balance, la cuenta de pérdidas y ganancias, la memoria y, en su caso, el estado de cambios de patrimonio neto y el estado de flujos de efectivo y la memoria y, a través de su lectura y análisis de estos documentos, se puede conocer, de manera gráfica y sencilla, la situación económico-financiera y patrimonial de una empresa, sin necesidad de examinar todos los libros contables.

\subsubsection{La comunicación y la exhibición de la contabilidad}

Se trata también de una excepción al deber de secreto de la contabilidad desde el momento en que la comunicación y exhibición de la contabilidad trata situaciones en los que los particulares pueden acceder al conocimiento de toda la contabilidad de un empresario o parte de ella en la fase de prueba de un procedimiento judicial (art. 32.2 CCom) (Gutiérrez, 2015: 36-37). La comunicación implica un reconocimiento general o universal de la contabilidad siendo el objeto de la comunicación el conjunto de libros, documentos contables, justificantes y correspondencia del empresario. La exhibición, sin embargo, constituye un reconocimiento parcial, es decir, de asientos o de documentos contables determinados que tengan relación con la cuestión que se trate en el procedimiento. Por ello, hay que establecer de manera precisa lo que se pretende que sea objeto de exhibición cuando la persona a quien pertenezca la contabilidad tenga responsabilidad en el asunto (art. 32.3 CCom) (Eizaguirre, 2005: 288; Rojo, 2015: 128).

Tanto la comunicación como la exhibición suponen una ruptura del principio del secreto de las comunicaciones y por ello solo el juez puede decretarlo, de 
oficio o a instancia de parte en supuestos previamente establecidos en las leyes. Los supuestos en los que las leyes permiten la vulneración del secreto de la contabilidad se encuentran tasados y son:

— Casos de sucesión universal.

— Liquidaciones de sociedades o entidades mercantiles.

- Expedientes de regulación de empleo.

- Supuestos en los que los socios tienen derecho a examen directo.

- Supuestos en los que los representantes legales de los trabajadores tengan derecho a su examen directo.

- Cuando la persona a quien pertenezcan tenga interés o responsabilidad en el asunto en que proceda la exhibición. En este supuesto se realizará una exhibición parcial, centrándose exclusivamente en los extremos necesarios para esclarecer cuestiones relacionados con el caso a tratar.

- Concurso de acreedores: un caso especial de comunicación es la existente en el concurso de acreedores. Declarado el concurso el deudor o los administradores de la sociedad deudora deben poner a disposición de la administración concursal, sin limitación alguna, los libros de llevanza obligatoria y cualesquiera otros libros, documentos y registros relativos a la actividad desarrollada. A solicitud de la administración concursal, el juez debe adoptar las medidas que estime necesarias para la efectividad de esta comunicación (art. 45 LC). Se trata, pues, de una comunicación a la administración concursal, como órgano del concurso, y no de una comunicación a los singulares acreedores.

El reconocimiento, tanto general como parcial, deberá llevarse a cabo en el establecimiento del empresario, y en presencia de éste o de la persona que comisione (art. 33.1 CCom). No obstante, por excepción, el juez o Tribunal, mediante resolución motivada, podrá reclamar que se presenten ante él los libros o el soporte informático de la contabilidad, especificando los asientos que deben ser examinados (art. 327 LEC y art. 114.2 JJV). Si el reconocimiento se efectúa a instancia de parte, el sujeto que lo solicite podrá servirse de auxiliares técnicos en la forma y número que el juez estime necesarios (art. 33.2 CCom). El juez adoptará, además, las medidas oportunas para la debida conservación y custodia de los documentos contables del empresario (Rojo, 2015: 128).

La solicitud de exhibición de libros, documentos y soportes contables, que habrá de fundarse en una ley que así lo establezca, se lleva a cabo mediante un expediente de jurisdicción voluntaria de acuerdo a la Ley 15/2015, de 2 de julio, de Jurisdicción Voluntaria, que requiere abogado y procurador y cuya competencia corresponde al Juzgado de lo Mercantil del domicilio de la persona 
obligada a la exhibición (art. 113 LJV). Si se estima la solicitud, la persona obligada tiene el deber de colaborar y facilitar el acceso a la documentación requerida para que el solicitante pueda proceder a su examen (art. $115 \mathrm{LJV}$ ), de modo que, en caso de negativa injustificada, obstaculización o quebrantamiento de ese deber, se prevé imposición de multas (art. 116 LJV).

\subsubsection{Publicidad de la contabilidad frente a las Administraciones Públicas}

Se trata de supuestos en los que el secreto de la contabilidad no opera frente a la Administración Pública, sea por razones fiscales (art. 142 LGT) ${ }^{11}$ o por el control público a que están sometidas determinadas entidades por razón del sector en que operan (como sucede con entidades de crédito por parte del Banco de Espańa o con las entidades de seguros por parte de la Dirección general de Seguros).

\subsection{Eficacia probatoria de la contabilidad}

La contabilidad puede ser un medio probatorio de extraordinario valor en los procedimientos judiciales. Pero la contabilidad constituye un medio probatorio más habiendo perdido la condición de medio de prueba privilegiado. El Código de Comercio afirma que «el valor probatorio de los libros de los empresarios y demás documentos contables será apreciado por los Tribunales conforme a las reglas generales del Derecho» (art. $31 \mathrm{CCom}$ ) y, en este sentido, se ha defendido que la contabilidad solo acredita hechos y no actos jurídicos ya que los contratos no son objeto de anotación contable (Rojo; 2015: 129).

\section{Bibliografía}

Alcover Garau, Guillermo (2011): «Las cuentas anuales», Revista de Derecho de Sociedades, núm. 36.

Arana Gondra, F. Javier (2000): Las cuentas anuales de la sociedad de responsabilidad limitada, Derecho Reunidas, Madrid.

Arribas Hernández, Alberto (2011): «La responsabilidad de los administradores sociales y personas afectadas por la calificación", Revista de Derecho concursal y paraconcursal: anales de doctrina, praxis, jurisprudencia y legislación, n. ${ }^{\circ} 14$.

11 El art. 142 de la Ley 58/2003, de 17 de diciembre, General Tributaria establece que «Las actuaciones inspectoras se realizarán mediante el examen de documentos, libros, contabilidad principal y auxiliar, ficheros, facturas, justificantes, correspondencia con transcendencia tributaria, bases de datos informatizadas, programas, registros y archivos informáticos relativos a actividades económicas, asi como mediante la inspección de bienes, elementos, explotaciones y cualquier otro antecedente o información que deba de facilitarse a la Administración o que sea necesario para la exigencia de las obligaciones tributarias». 3. Los obligados tributarios deberán atender a la inspección y le prestarán la debida colaboración en el desarrollo de sus funciones. (León, 1997; Eizaguirre, 2005). 
Blanco Campaña, Jesús (1980): Régimen jurídico de la contabilidad, Ministerio de Justicia, Madrid.

Boquera Matarredona, Josefina (2002): «Aprobación de las cuentas anuales y derecho de información del socio en la sociedad anónima y en la sociedad de responsabilidad limitada", Derecho de Sociedades. Libro Homenaje a Fernando Sánchez Calero, vol. II, Madrid.

Broseta, Manuel y Martínez Sanz, Fernando (2016): Manual de Derecho Mercantil, Tecnos, Madrid, 23. ${ }^{\circ}$ edición.

Cábanas Trejo, Ricardo (2012): "Cierre registral por falta de depósito de cuentas anuales: ¿puede el Registrador Mercantil calificar la causa de la falta de aprobación?», Reglamento hipotecario: (con las modificaciones introducidas por la últimas sentencias del Tribunal Supremo) y Estudios juridicos en torno a la calificación registral y la inscripción a la luz de dicha jurisprudencia, Madrid.

Campins Vargas, Aurora (2012): «Reforzamiento jurisprudencial del derecho de información de los accionistas en materia de cuentas anuales», Revista de Derecho Mercantil, núm. 284.

Cano, J. R., (2010): «El depósito de cuentas anuales en España», Partida Doble, n. 227.

Del Puerto, Leopoldo (2011): Formulación de cuentas anuales en las sociedades de capital, Ed. Reus, Madrid.

Díaz Moreno, Alberto (2002): «Dudas, reflexiones y precisiones acerca del depósito de cuentas en soporte informático y a través de procedimientos telemáticos», Derecho de Sociedades. Libro Homenaje a Fernando Sánchez Calero, vol. II, Madrid.

Eizaguirre, José María (2005): Derecho Mercantil, 4. ${ }^{\circ}$ edición, Civitas ediciones Madrid.

Gallego Córcoles, Ascensión (2014): «Evolución de la vacilante posición de la DGRN en materia de rechazo de depósito de cuentas anuales en los casos de informe de auditor con opinión denegada por limitaciones al alcance de la auditoría», La Ley mercantil, n. ${ }^{\circ}$ 3, 2014.

García-Cruces González, José Antonio (2013): «Declaración de concurso y acciones societarias de responsabilidad frente a los administradores de la sociedad concursada", Anuario de Derecho Concursal, n. ${ }^{\circ} 28$.

Girón Tena, José (1993): «Las cuentas anuales de la sociedad anónima», Revista de Derecho de Sociedades, n. ${ }^{\circ} 1$.

Gómez Porrua, Juan Manuel (2007): "Denegación de depósito de cuentas anuales», Derecho de los negocios, Año n. ${ }^{\circ} 18$, n. $^{\circ} 205$.

Gómez Porrua, Juan Manuel (2007): «Depósito de cuentas anuales», Derecho de los Negocios, Año n. ${ }^{\circ} 18$, n.o 207.

Gurrea Martínez, Aurelio (2016): Recuperado el 20 de octubre de 2016 de http://almacendederecho.org/contabilidad-juristas-iv-las-cuentas-anuales-la-propuesta-aplicacion-del-resultado/.

Gutiérrez Gutiérrez, Angélica (2015): «La exhibición de libros contables en la nueva ley de jurisdicción voluntaria», Cont 4 bl3, n. ${ }^{\circ} 55$.

León SANZ, Francisco Javier (1997): La publicidad de las cuentas anuales en el Registro Mercantil, McGraw-Hill Interamericana de España, Madrid.

León SANZ, Francisco Javier (1998): «El cierre del registro mercantil: problemas que plantea su aplicación", Revista de Derecho de Sociedades, n. ${ }^{\circ} 10$.

Lopez Santana, Nieves en Jiménez Sánchez, Guillermo y Díaz Moreno, Alberto (Coord.) (2013): Derecho Mercantil, vol.3, 5. ${ }^{\mathrm{a}}$ ed., Marcial Pons, Madrid.

Martín Reyes, María Ángeles (2012): «La concurrencia de acciones en orden a la exigencia de responsabilidad a los administradores sociales», Anuario de derecho concursal, n. ${ }^{\circ} 26$. 
Miquel Rodríguez, Jorge (2011): "Conductas de los administradores que generan responsabilidad concursal. Análisis de jurisprudencia», en Embid Irujo, José Miguel; Roque Vítolo, Daniel y León Sanz, Francisco Javier (Dir.) (2011): Derecho de sociedades y concurso: cuestiones de actualidad en un entorno de crisis, Comares, Madrid.

Muñoz Planas, José María y Muñoz Paredes, José María (2005): «Repercusiones del concurso de la sociedad sobre la responsabilidad de los administradores», Estudios sobre la Ley Concursal: libro homenaje a Manuel Olivencia, vol. 2.

Rocafort Nicolau, Alfredo (2010): «El depósito de las cuentas anuales de las sociedades de capital en el Registro Mercantil», Revista de Derecho de Sociedades, n. ${ }^{\circ} 35$.

Rojo, Ángel (2015): «La contabilidad» en Menéndez, Aurelio y Rojo, Ángel (Dir.) (2015): Lecciones de Derecho Mercantil, vol. I, Thomson Civitas, Madrid.

Rodríguez DíAz, Isabel (2013): «La responsabilidad del representante del administrador persona jurídica en el concurso culpable», Anuario de Derecho Concursal, n.o 30.

Sánchez Calero Guilarte, Juan (2014): «Opinión de auditoría denegada y depósito de cuentas anuales», Revista de derecho bancario y bursátil, n. ${ }^{\circ} 136$.

Selva Sánchez, Luis M. (1993): «Depósito y publicidad de las cuentas anuales», Derecho de los negocios, Año n. ${ }^{\circ} 4$, n. ${ }^{\circ} 33$.

Vicent Chuliá, Francisco (2004): «Reforma contable y Derecho Mercantil», Revista de Contabilidad, vol. 7.

Yzquierdo Tolsada, Mariano (2013): «El seguro de responsabilidad civil de los administradores societarios, ante el concurso de acreedores calificado como culpable» en López y García de la Serrana, Javier y Sánchez Ruiz de Valdivia, Inmaculada (Coord.) (2013): Cuestiones actuales de responsabilidad civil, Aranzadi, Cizur Menor, 2013. 